\title{
Optics in Eastern Connecticut
}

\section{Nancy Magnani, Judith Donnelly}

Nancy Magnani, Judith Donnelly, "Optics in Eastern Connecticut," Proc. SPIE 9666, 11th Education and Training in Optics and Photonics Conference, 96660S (5 June 2009); doi: 10.1117/12.2208028

SPIE Event: Eleventh International Topical Meeting on Education and Training in Optics and Photonics, 2009, St. Asaph, United Kingdom 


\title{
Optics in Eastern Connecticut
}

\author{
Nancy Magnani \\ EASTCONN, 322 Main Street, Willimantic, CT 06226, USA
}

\author{
Judith Donnelly \\ Three Rivers Community College, 7 Mahan Drive, Norwich, CT 06030, USA
}

\begin{abstract}
Through a partnership between EASTCONN, a regional educational service center, and Three Rivers Community College, both located in eastern Connecticut, students from $5^{\text {th }}$ grade through college have been learning about optics and photonics. Using innovative approaches including hands-on workshops on selected topics in light, vision and optics/photonics, field trips to local photonics industries, and authentic learning opportunities at a college campus, students and their teachers are learning about light and optics with age-appropriate activities and are also being introduced to the potential career opportunities.
\end{abstract}

\section{INTRODUCTION}

Although many know only of Connecticut's "gold coast" adjacent to New York City, the two easternmost counties in the state are mostly rural low-income towns with a few small cities scattered here and there. Three of Connecticut's fifteen "priority" (lowest achieving) school districts are in Windham and New London Counties, and two of these districts have more than $70 \%$ of students qualifying for free or reduced price lunch. ${ }^{1}$ Median income is well below the state average and fewer residents hold college degrees. ${ }^{2}$ However, a thriving network of optics/photonics educators has evolved over the past 14 years despite the relatively low number of photonics employers in the region. The network continues to grow due to the leveraging of several sources of funding and the enthusiasm of the partners involved.

Through its National Science Foundation/Advanced Technology Education (NSF/ATE) grant-funded PHOTON projects, the New England Board of Higher Education (NEBHE) has involved high school and community college faculty in four teacher professional development programs in optics/photonics. Together with EASTCONN, one of Connecticut's six regional educational service centers, the PHOTON educators have received funding from SPIE, the Optical Society of America (OSA), the NSF/ATE funded Regional Center for Next Generation Manufacturing (RCNGM) and the Interdistrict grant programs funded through the state of Connecticut and facilitated by EASTCONN to bring together students from fifth grade through college in the study of optics and photonics (Figure 1).

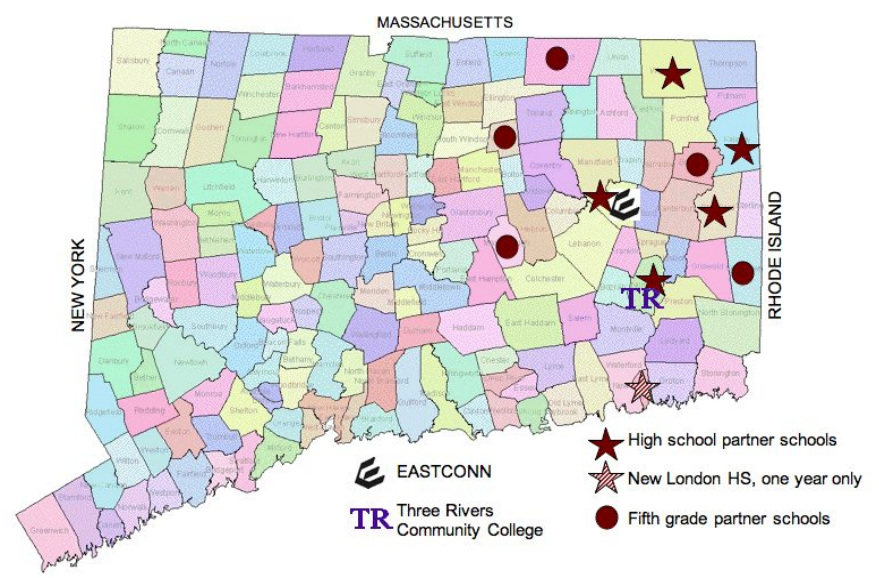

Figure 1. Eastern Connecticut optics education network

Eleventh International Topical Meeting on Education and Training in Optics and

Photonics, edited by K. Alan Shore, Deb Kane, Proc. of SPIE Vol. 9666, 96660 S

(C) 2009 SPIE, OSA, IEEE, ICO · doi: $10.1117 / 12.2208028$ 


\section{THE PHOTON PROJECTS}

Beginning with the first NSF/ATE grant in 1995, NEBHE has involved Connecticut educators in all four of the PHOTON projects which were designed to increase the number of schools and colleges teaching optics/photonics. ${ }^{3}$ One of the authors (J.D.) was a participant in the first project, the Fiber Optic Technology Education Project (FOTEP) and with the support and encouragement of the FOTEP principle investigators, developed an associate degree in Laser and Fiber Optic Technology at Three Rivers Community College, located in southeastern CT. This remains the state's only two-year program in optics/photonics. In 2007, a second photonics-related program was created when a Laser Manufacturing option was added to the Manufacturing Engineering Technology associate degree program after a needs survey of manufacturers in southern New England.

The second PHOTON project expanded the scope of technology covered in professional development workshops to include optics and lasers and it included high school teacher participants from two eastern CT high schools, H.H. Ellis Technical High School and Plainfield High School. PHOTON introduced a "regional alliance" model that encouraged high schools and colleges to work together to improve access and articulation for students. As alliance partners, Three Rivers, Ellis Tech and Plainfield HS began to explore ways they could work together, beginning with informal tours and workshops for high school students held at the college. Teachers from the three institutions were also involved in PHOTON2 and PHOTON PBL (Problem Based Learning), projects with a national scope that strengthened the Connecticut alliance through collaboration with distant partners and industry mentors.

The PHOTON projects produced a number of educational products that have been used in workshops and outreach activities as well as in classroom settings, including a textbook, a laboratory kit with experiment manual and a set of online videos, and instructions for simple optics Explorations also with online video presentation. ${ }^{4}$

\section{PROGRAMS FOR ELEMENTARY SCHOOL}

\subsection{Fifth grade Optics in the Classroom}

The collaboration between Three Rivers Community College and EASTCONN began in 2006 when light and vision were added to the Connecticut science curriculum for $5^{\text {th }}$ grade students; these concepts were added to the Connecticut Mastery Test (CMT) in 2008..$^{5}$ In order to prepare students for the test, a standards-based workshop was developed to introduce optics concepts to fifth grade students. The workshop, Optics in the Classroom, has been offered each year since 2006, with facilitators from EASTCONN and the Three Rivers Student Chapter of SPIE. The day-long workshops feature three concurrent activities lasting approximately one hour each.

To create lessons that would satisfy the needs of younger students, hands-on activities were adapted from the PHOTON Explorations and the Hands-on-Optics project. ${ }^{6}$ The activities selected cover concepts from the Connecticut Core Science Curriculum Framework Content Standards and Expected Performances - Core Science for grades 3-5. Students are expected to not only perform the activities but also to record observations and draw conclusions based on their observations (Figure 2). Activities chosen for Optics in the Classroom have varied somewhat from year to year and have included:

- Make-and-take Spectroscopes. Students make spectroscopes from cardboard tubes, diffraction gratings and laser-cut poster board slits. (The slits are cut by students at Three Rivers on an Epilog $45 \mathrm{~W}$ laser engraver.) After observing a number of light sources such as incandescent and fluorescent bulbs, LEDs and gas tubes, students take the spectroscopes home to continue their observations. This activity also stresses safe observations by asking students to affix a warning to the tube stating "Do not look at the sun or into a laser!" Some time is spent discussing the dangers of observing bright light sources.

- Gelatin Optics. Students use a laser pointer and gelatin slab to study refraction and absorption of light and cut lens shapes to investigate how light behaves at a curved surface. Again, strict laser safety rules are imposed and students who do not follow the rules are told to sit out the activity. 
- The "Magic Box". This activity uses four polarizers to create the illusion of a solid wall inside a cardboard box. The activity contrasts "descriptive writing" and "scientific writing" and students are required to write scientifically about what they see.

- The Mirror Challenge. Students are introduced to the law of reflection and then must use that knowledge and a protractor to position mirrors in order to hit a target with the beam from a laser pointer. Again, laser safety is stressed.

- Waves and Sound. Students make waves with beaded chains and Slinky® toys and measure wavelength and amplitude. The relationship between wavelength and sound is explored.

After each workshop, students have been asked to fill out an evaluation form and discuss their favorite activity. The overall favorite varies from year to year and may be somewhat dependent on the facilitator. For example, in 2009 students particularly liked the Mirror Challenge, led by two enthusiastic young men from the Three Rivers SPIE Student Chapter. In four years of workshops, nearly 500 students from four eastern Connecticut towns have been impacted by the Optics in the Classroom program.
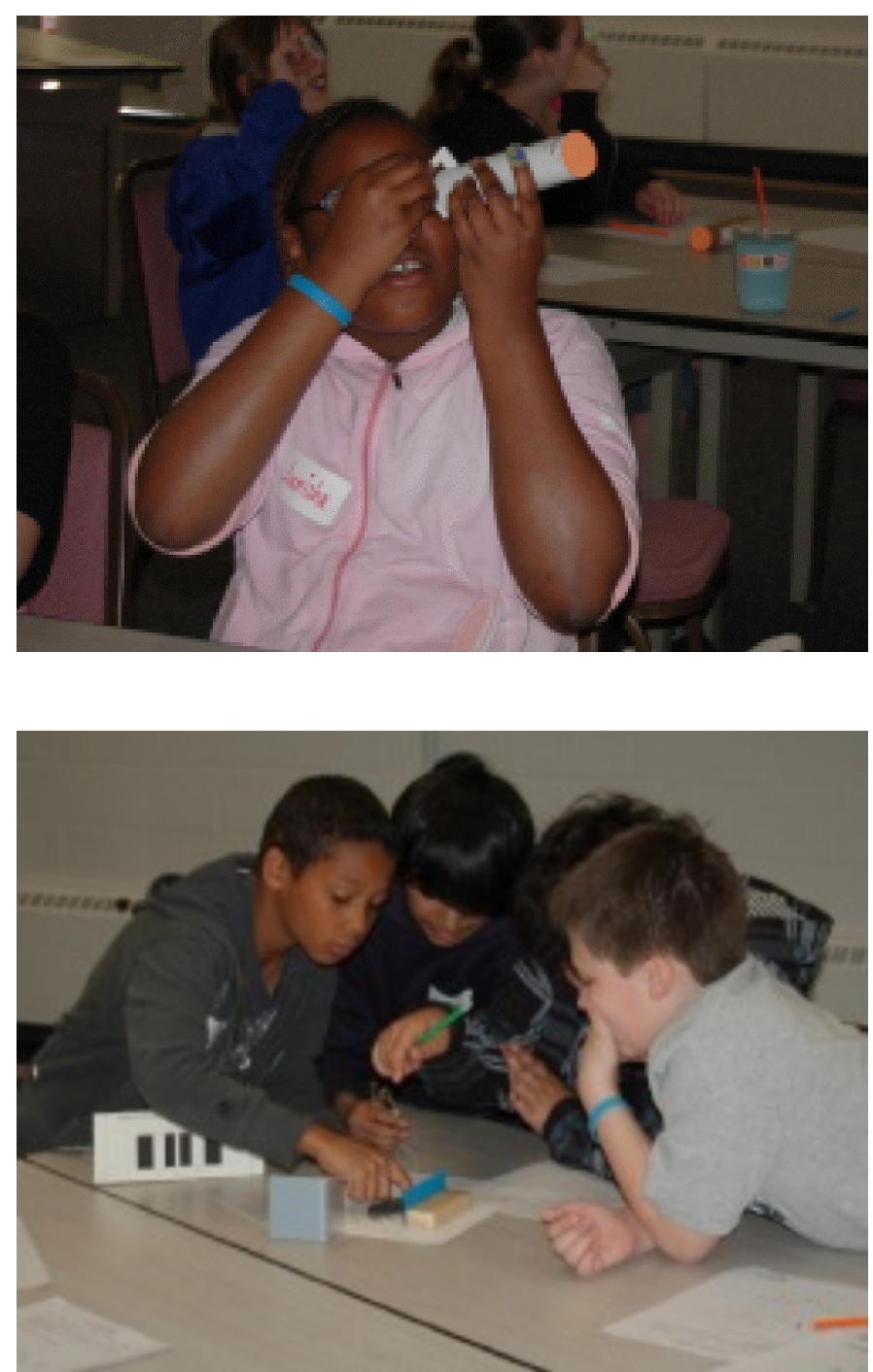

Figure 2. top: Fifth grade students make the cardboard tube spectroscope from the PHOTON Explorations and use it to study the emission spectra of various light sources. Bottom: Protractors are used to line up a "shot" taken with a laser pointer in the Mirror Challenge from Hands-on-Optics. 


\subsection{Professional development for teachers}

Although the workshops for students have been very successful, more students would benefit from our lessons if their teachers were able to conduct them in their own classrooms, reinforcing the concepts and answering individual student questions. To meet the need for teacher professional development in optics, we developed a workshop for teachers in which hands-on activities, scientific inquiry, and scientific literacy are combined to deepen understanding and interest in optics. The yearly workshop has evolved to include some commercially available science materials as well as those developed by PHOTON and Hands-on-Optics. Since 2007, 75 teachers from across Connecticut have participated in the yearly EASTCONN optics workshops.

Even after attending a workshop, some teachers are still reluctant to teach the material because of a lack of background in the subject. To assist these teachers, we provide ongoing technical support and encouragement. Other teachers face the lack of funding to purchase supplies needed for hands-on activities. Through a three-year grant from the OSA Foundation, EASTCONN has purchased a number of Hands-onOptics kits and made them available to teachers who have been trained in their use.

\subsection{Dark Skies at EASTCONN}

Dark Skies at EASTCONN is a multifaceted program generously funded by the OSA. The program is part of EASTCONN's Expanding Horizons, an interdistrict diversity program funded through the state of Connecticut. Expanding Horizons encourages teams of students from diverse backgrounds in grades 5-12 to build positive relationships, critical thinking and problem solving skills while working together in cross-district partnerships on authentic science based projects. High school and college students also participated in Dark Skies on an individual basis through their teachers' participation in other EASTCONN projects.

In the Dark Skies project, students from $5^{\text {th }}$ grade through college measured the brightness of the nighttime sky using sky quality meters and visual observations of the constellation Orion and then compared the results with national and international student partners. Participating students were from the states of Connecticut, Alaska, Ohio, and New York, as well as New Brunswick, Canada, Wales and Slatina, Romania. Student data is included in our own database for future studies of light pollution and also forwarded to the National Optical Astronomy Observatory (NOAO), Tucson, AZ, and contributed to Globe at Night, an international project to measure the brightness of the night sky. ${ }^{7}$

The initial kickoff meeting in Fall 2008 introduced teachers to the program and featured Bob Crelin, Connecticut author of There Once Was a Sky Full of Stars, a book about light pollution for young children. Each participating teacher received a copy of Crelin's book purchased with funds from RCNGM. Throughout the fall and early winter, instructional materials were developed to introduce students to the use of the meters and observation and data sheets. Students from a middle school technology class created a set of videos illustrating how to hold and read the meters and record data properly. While the facilitators were busy with developing materials, the fifth grade students wrote pen-pal letters to their distant partners, introducing themselves, their families and schools.

Each of the participating schools received a kit of materials purchased with funds from the OSA Foundation grant (Figure 3). In addition to the Crelin book, each kit contained demonstrations to illustrate the effects of light pollution and how shielding outdoor lighting both improves vision and preserves the night skies. Each class received two sky quality meters so that students could take quantitative as well as qualitative data.

In the first year of the project (2008) the students attended a final workshop where they constructed and used a simple refracting telescope from the Hands-on-Optics kit. Two special guests from NOAO led the activities, assisted by students from Three Rivers and a volunteer amateur astronomer who amazed students with his own "professional model" telescope. For 2009, students attended the telescope workshop before taking data; this workshop was facilitated by students from the Plainfield High School after school Astronomy Club. A second workshop at the end of the project featured a rented indoor planetarium in addition to optics activities.

Another new feature in 2009 was a video conference with Dr. Constance Walker, an astronomer at NOAO, who shared her knowledge with students and teachers from Connecticut, Canada, Ohio and Romania. Participants used Skype, free software for internet telephone, and Bridget desktop-sharing software. This system was also used to enable the students to share and comment on their Dark Skies data. 
Future Dark Skies at EASTCONN plans include an ongoing study of the brightness of the nighttime sky with an ever-expanding group of students. In addition, in celebration of the Year of Astronomy, students will be making Galileoscopes in an online class. Dark Skies at EASTCONN is unique because students engage in authentic scientific study while also enhancing their global awareness through an international partnership and study of the nighttime sky. To date, two high schools, two colleges and four elementary schools in the US and their partner schools in have taken part in Dark Skies at EASTCONN.

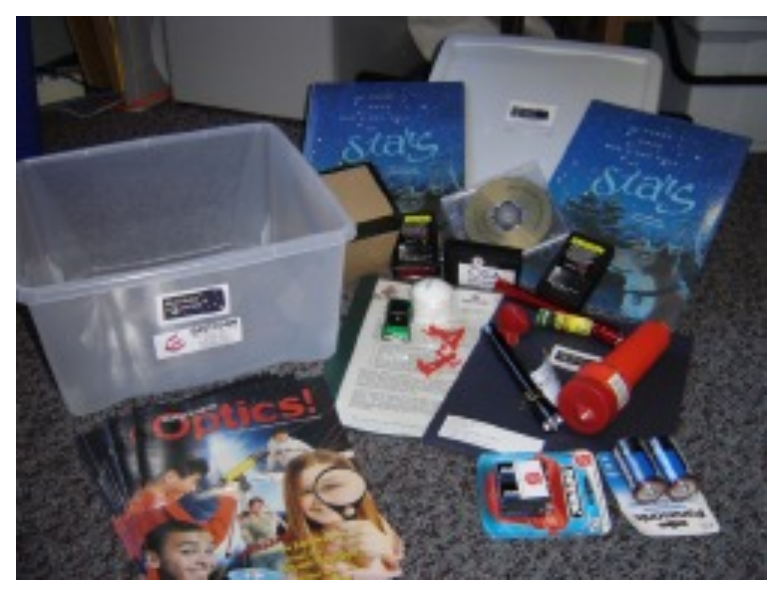

Figure 3. The Dark Skies activity kit

\section{HIGH SCHOOL AND COLLEGE PROGRAMS}

\subsection{High school courses}

Through PHOTON and PHOTON2, both Plainfield High School and Ellis Technical High School received laboratory kits for teaching optics/photonics containing both "science lab" and industry quality materials. Through the College Career Pathway (formerly Tech Prep) each school purchased additional materials to support a complete optics laboratory. Both schools then developed optics/photonics elective courses for their institutions.

At Plainfield High School, the course closely follows Three Rivers' PHO 101 Introduction to Light and Lasers. The high school course has been approved as either a science or technology elective in the College Career Pathway agreement between the high school and the college. This means that students enrolled in the College Career Pathway program can earn 3 college credits for the optics/photonics course when it is taken as part of their high school program. Students in the College Career Pathway can earn up to 14 college credits in math, English communications, science and a career area while still in high school.

While the students at Plainfield High School all reside in the town of Plainfield, Ellis Tech serves approximately 600 students from seventeen towns in northeast Connecticut. Ellis Tech is a "school of choice," that is, students are accepted based on standardized test scores and other academic records from middle school. At the end of their freshman year, students choose from among ten specialized areas of study: architectural technologies, automotive collision repair, automotive, carpentry, electronics, electrical, hairdressing and barbering, manufacturing, masonry, and plumbing and heating.

Three Ellis Tech teachers, two from the sciences and one from a technical shop along with a guidance/career counselor participated in the PHOTON and PHOTON2 projects. The full-year Introduction to Optics course was developed by science teacher Donna Goyette with support from the Regional Center for Next Generation Manufacturing. The course is based on the instructional units of the PHOTON and PHOTON2 professional development courses. The technical high school year is divided into eighteen ten-day cycles; one half of the time is spent in academics (mathematics, science, English, humanities and social science, as well as health and physical education) alternating with units in a technical/trade shop. To accommodate this cycle, 
Introduction to Optics is structured in nine ten-day units, equivalent to a one-half year course at a comprehensive (non-technical) high school. ${ }^{9}$

The technical high school optics course is unique in that it uses a hands-on, discovery-based approach integrated with examples from the technology and trade shops at the school. Goyette visited each of the shops to learn where optics was used in each technology. For example, in the automotive shop students learn to troubleshoot automotive optical systems and student hairdressers and barbers see applications of optics in the color pigments of hair dye. Every optics unit is infused with examples from the shops, and learning optics in a science class increases student confidence when they return to the shop environment. Since many technical high school students have difficulty with or are fearful of mathematics, the discovery approach allows them to learn concepts through inquiry-based experimentation and activities. The need for mathematical analysis arises naturally from student observations.

\subsection{College Programs}

Three Rivers Community College has the only optics/photonics two-year associate degree program in Connecticut, Laser and Fiber Optic Technology (LFOT). ${ }^{10}$ Created in the mid 1990's with assistance from the FOTEP project principle investigators and an industry advisory committee, the program has continuously evolved to keep up with industry needs. Originally focusing mainly on fiber optic communications, LFOT has added courses and course modules in lasers and laser applications as these technologies have become increasingly important in Connecticut. LFOT graduates are employed as technicians in the optics/photonics industry of Connecticut and across the United States.

The LFOT program has also worked with agencies in Connecticut to provide training for both displaced and incumbent workers, including two-day fiber optic workshops, a 15 credit telecommunications certificate offered to workers at a fiber optics company using a combination of online and in-person instruction and noncredit 40 hour laser technology courses taught on site at several laser manufacturing companies. A LFOT certificate has been developed to serve the needs of working technicians whose primary training is in electronics or manufacturing technology. Some of the courses are offered online or and online/in class hybrid versions.

\subsection{Laser Camp}

For several years, Three Rivers Community College received grant funding from SPIE to offer a summer credit course in optics/photonics to high school students. As college fees increased, fewer students were served and it was no longer practical to offer the course. At the 2006 meeting of the Laser and Fiber Optic Technology Industry Advisory Committee, member Donna Goyette suggested we apply for funding for a "Laser Camp," a multi-day activity that would introduce students to optics/photonics science, technology and careers. Laser Camp would target high school juniors at Ellis Tech, perhaps encouraging them to sign up for Introduction to Optics in their senior year.

The first Laser Camp was held in 2007 with students from Ellis Tech, New London High School and members of a Scout troop from Plainfield, CT. A few middle school students, friends and relatives of facilitators, also participated. The New London physics teacher had also been a PHOTON project participant and the Plainfield students were in a troop mentored by a Three Rivers SPIE student chapter member. It was decided to hold activities during the school year when students are easily contacted and on Saturdays as a college event to avoid high school travel restrictions and the need for hiring substitute teachers. The 2007 Laser Camp was funded by grants from SPIE and RCNGM and was attended by 30 middle and high school students and six college student mentors. Three teachers/faculty served as facilitators.

Two days of workshops took place in the Three Rivers labs; students created reflection holograms, made pinhole cameras and learned to develop the photos, tried online laser challenges and made laser engraved and cut wooden key tags. Each participant received a tee shirt and took home the items they made as part of the camp. The third day was a trip by motor coach to Boston, MA to visit the Science Museum and the Massachusetts Institute of Technology Museum in Cambridge (Figure 4). Student evaluations of Laser Camp were extremely enthusiastic and it was clear that this activity would need to continue in some form as long as funding could be secured. Three students from Laser Camp 2007 subsequently enrolled in laser-related programs at Three Rivers. 


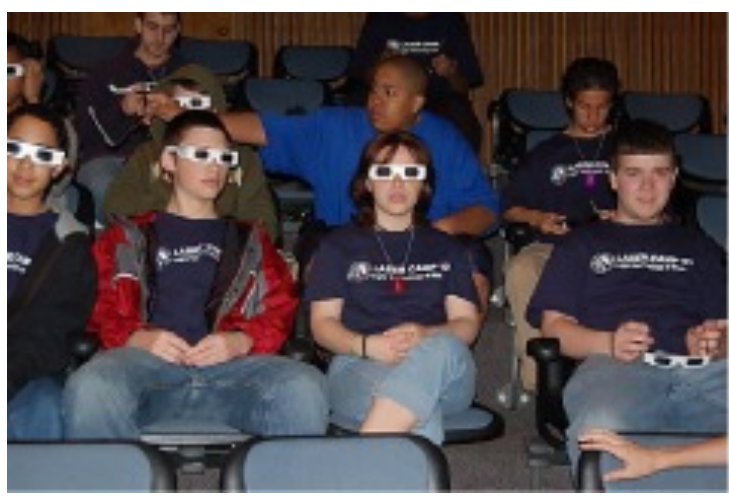

Figure 4. Laser Campers (2007) at a 3-D Imax movie at the Boston (MA) Museum of Science. Before the movie began, students were asked to figure out how the glasses work.

Laser Camp continues to grow; 43 students from four high schools attended in 2008 and 62 students from five high schools in 2009 (Figure 5). Beginning in 2008, collaboration with EASTCONN's Expanding Horizons grant provided funding for the transportation from distant high schools to Three Rivers, a major portion of the budget. Additional funding still comes from grants from SPIE and RCNGM. Because the EASTCONN funding precludes Saturday activities, Laser Camp is now held on three regular school days with two days at Three Rivers and a third day visiting the laser manufacturing and applications facility at Trumpf, Inc. in Farmington, $\mathrm{CT}$. Scheduling three days away from school has proven to be problematic; school vacations, standardized testing, the technical high school academic and shop cycles and the availability of the Three Rivers labs all must be considered. In 2009 , one session was repeated on two different days to accommodate the technical and comprehensive high school schedules.

The Laser Camp curriculum has expanded to include EASTCONN facilitated team building activities among students from different high schools and it still includes a number of activities that produce "take-aways" that students can show off when they return to school. In addition to pinhole cameras, holograms and laser engraved key tags, a "polarized light art" activity has been added. Students create colorful "art" by sandwiching laser cut cellophane shapes between squares of polarizing film. Three Rivers pens, Laser Camp tee shirts and logo bags of college and program information are given to each student as well.

When Laser Camp was a small Saturday activity, the facilitators were the three high school and college faculty. College students served as mentors and assistants. The growing size of Laser Camp required additional facilitators, so the Three Rivers SPIE student chapter has taken up the task of leading activities, including providing background information on the science and technology involved. In 2009, ten SPIE members helped out as activity leaders and assistants, serving as role models to the high school students while sharpening their own leadership skills.

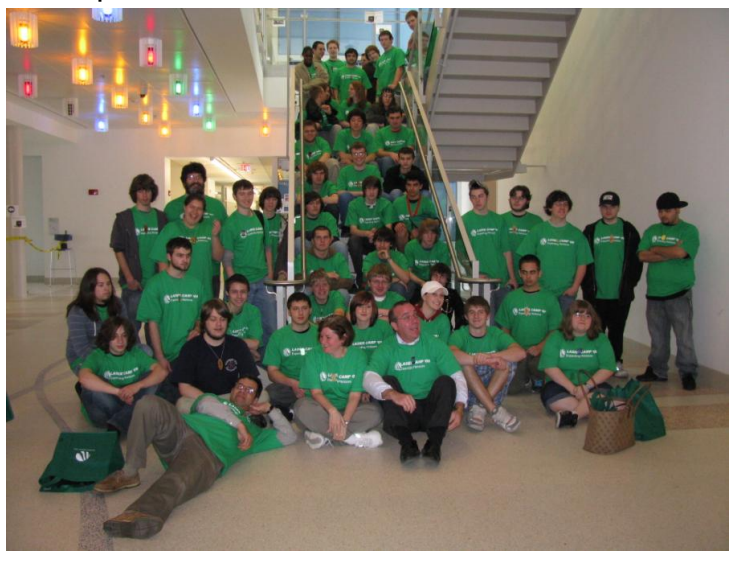

Figure 5. Laser Camp 2009. 


\section{INTERNATIONAL POSTER CONFERENCE}

Light in our Life, an international poster contest for students, was first planned by Romanian participants in PHOTON PBL and the authors during the summer 2008 PHOTON PBL workshop in Boston. A limited contest was piloted in the spring of 2009. Invitations to submit poster art were sent to the Dark Skies at EASTCONN schools and selected schools in Europe. Entries could be in one of three categories: photograph, hand drawn or painted or computer art. Entrants were also required to submit a 100 word statement on how their entry illustrates the theme, Light in our Life.

Two groups of science, technology and art educators screened the entries from each continent before submitting the top few in each category for final judging. Entries were judged on artistic impression, technical merit, originality, and how well the art expresses the theme of the contest. Trophies were presented to winners in two age groups, 10-13 years and 14-18 years, in each of the three art categories. Each winner and honorable mention entry also received a certificate and a copy of their art rendered as a poster. Classroom teachers of winners also received a set of the winning posters. Figure 6 shows the winners in the 14-18 year old photography and the 10-13 year old drawing/painting categories.

The 2009 contest was supported by SPIE, which provided the trophies, and the OSA Foundation grant, which was used to print the posters. The planners hope to expand the contest next year by adding additional schools in more countries.
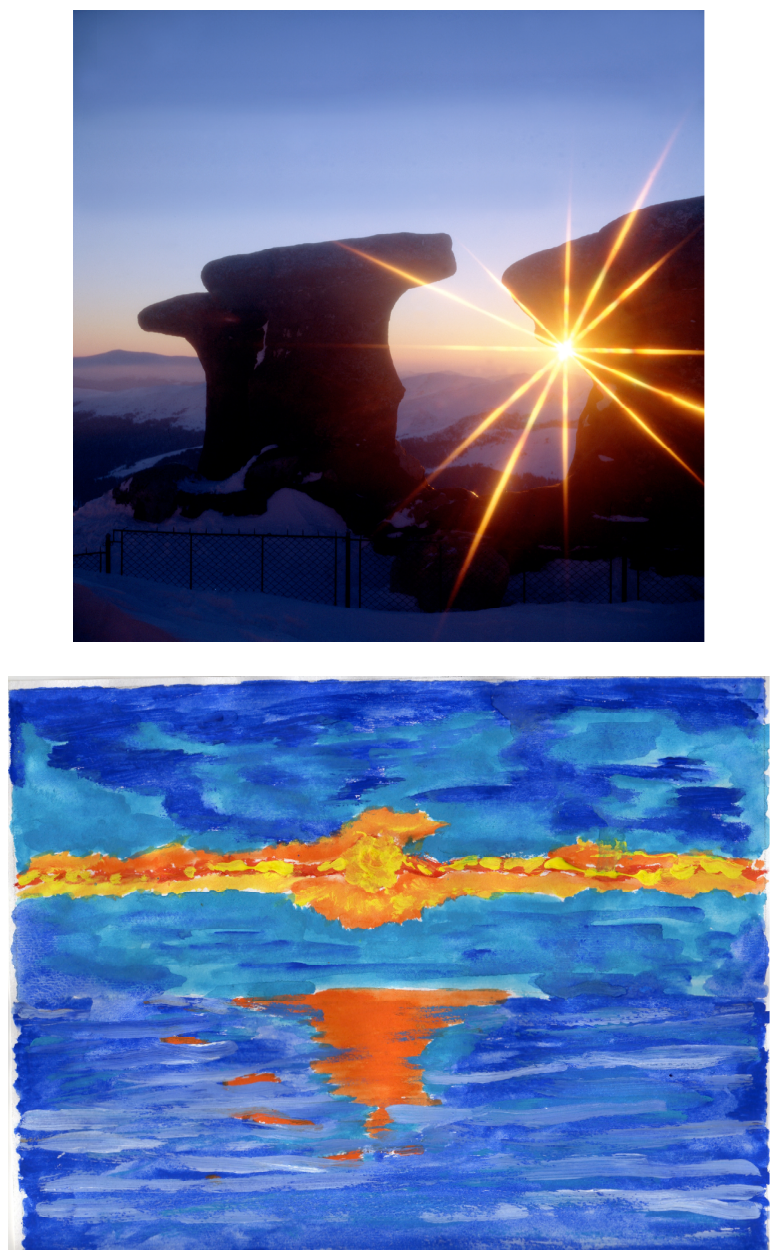

Figure 6. Two of the winning entries in the Light in our Life poster contest: (top) Age 14-18 Photograph (bottom) Age 10-13 Painting /Drawing 


\section{CONCLUSION}

Through collaboration and pooling of resources, schools and organizations in eastern Connecticut have created a network of educators, students and industry working to promote optics and photonics education and careers. The network continues to grow by leveraging grant funding from a number of sources and including present and former students as mentors and advocates for optics/photonics.

\section{REFERENCES}

[1] Ct State Dept of Education, www.csde.state.ct.us/

[2] U.S. Census Bureau www.census.gov

[3] Donnelly, J.F., Hanes, F.D., and Massa, N. M. Professional development in photonics: The advanced technology education projects of the New England Board of Higher Education, SPIE Optics and Photonics, Proceedings Vol. 6668 (2007)

[4] PHOTON project materials, including Laboratory and Exploration videos, are available at www.photonprojects.org [5] Magnani, M. and Donnelly, J.F. Innovative methods to teach optics in the grade 5 classroom Proceedings of the 2007 ETOP Conference, Ottawa, Ontario, CA (2007).

[6] Hands-on-Optics information is found at www.hands-on-optics.org/

[7] Globe at Night is a project of the GLOBE project, www.globe.com/GAN

[8] Components of the PHOTON Laboratory Kit may be seen at www.photonrpojects.org

[9] Goyette, D.M. and Donnelly, J.F. Interdisciplinary Optics Course for Technical High Schools, SPIE Optics and Photonics, Proceedings Volume 7061, pp. 70610T-70610T-8 (2008).

[10] Program information may be found at www.lasertechonline.org

\section{ACKNOWLEDGEMENTS}

FOTEP

Funded in part by the Advanced Technological Education program of the National Science Foundation (ATE\# 9553762). Principal Investigator, Nicholas Massa, Springfield Technical Community College

PHOTON

Funded in part by the Advanced Technological Education program of the National Science Foundation. (ATE\# 0053284) Principal Investigator, Judith Donnelly, Three Rivers Community College

\section{PHOTON2}

Funded in part by the Advanced Technological Education program of the National Science Foundation.(ATE\# 0302528) Principal Investigator, Fenna Hanes (Project Manager), New England Board of Higher Education

PHOTON PBL

Funded in part by the Advanced Technological Education program of the National Science Foundation.(ATE\# 0603143) Principal Investigator, Fenna Hanes (Project Manager), New England Board of Higher Education, Website: www.photonprojects.org.

\section{EXPANDING HORIZONS}

Interdistrict diversity program for grades 5-12 administered by EASTCONN and funded through the Connecticut State Department of Education. EASTCONN, 376 Hartford Turnpike, Hampton, CT 06247

REGIONAL CENTER FOR NEXT GENERATION MANUFACTURING

Funded in part by the Advanced Technological Education program of the National Science Foundation.(ATE\# 0402494) Principal Investigator, Karen Wosczyna Birch, Connecticut Community Colleges

\section{OSA FOUNDATION}

The OSA Foundation is a charitable organization dedicated to supporting programs that advance youth science education, provide optics education and resources to underserved populations, provide career and professional development resources and support awards \& honors that recognize technical and business excellence 